\title{
Surgical management of cholesteatoma cases: An experience of 50 cases
}

\author{
Shailesh Bhaginath Nikam ${ }^{1 *}$, Vasant Gangadhar Pawar ${ }^{2}$
}

\author{
${ }^{1}$ Assistant Professor, ${ }^{2}$ Associate Professor \& HOD, Department of ENT, Government Medical College, Aurangabad, Maharashtra, INDIA. \\ Email: nshailesh87@gmail.com
}

\begin{abstract}
Background: Cholesteatoma represents the presence of a non-neoplastic accumulation of keratinizing stratified squamous epithelium along with desquamated keratin debris in the tympanic cavity and / or mastoid. Surgical management may range from a simple extraction of cholesteatoma to a radical mastoidectomy Aim \& objective: To study the surgical management of cholesteatoma patients at a tertiary health care centre Methodology: Present study was an observational study carried out on Patients coming to ENT outpatient department and diagnosed with cholesteatoma. Data was collected with pre tested questionnaire. Data included demographic data, Clinical history, Present complaints, investigations and treatment modalities were noted. Data was analysed with appropriate statistical tests. Results \& discussion: Posterosuperior retraction (56\%) was the most common type of tympanic membrane finding seen, followed by attic retraction (40\%). $60 \%$ of the patients underwent canal wall down procedures and $40 \%$ canal wall up procedures. In $80 \%$ of the patients some form of middle ear reconstruction was done whereas in $20 \%$ of patients no reconstruction was undertaken. $25 \%$ of the patients who had undergone radical mastoidectomy had a middle ear reconstruction done as compared to $67 \%$ of modified radical mastoidectomies.
\end{abstract}

Key Word: cholesteatoma.

*Address for Correspondence:

Dr Shailesh Bhaginath Nikam, Assistant Professor, Department of ENT, Government Medical College, Aurangabad, Maharashtra, INDIA.

Email: nshailesh87@gmail.com

Received Date: 04/06/2020 Revised Date: 19/07/2020 Accepted Date: 13/08/2020

DOI: https://doi.org/10.26611/10161533

This work is licensed under a Creative Commons Attribution-NonCommercial 4.0 International License. $(\mathrm{cc})$ ) EY-NC

\begin{tabular}{|l|l|}
\hline \multicolumn{2}{|c|}{ Access this article online } \\
\hline Quick Response Code: & Website: \\
\hline & www.medpulse.in \\
\cline { 2 - 2 } & \\
\hline
\end{tabular}

\section{INTRODUCTION}

"Cholesteatoma is a three dimensional epidermal and connective tissue structure, usually in the form of a sac and frequently conforming to the architecture of the various spaces of the middle ear, attic and mastoid. This structure has a capacity for progressive and independent growth at the expense of underlying bone and has a tendency to recur after removal." 1 Cholesteatoma can be classified as Congenital or Acquired depending on the origin. It can be classified as inactive and active cholesteatoma depending upon the activity. ${ }^{2}$ Macroscopically, cholesteatoma appears as a roundish or oval shaped friable mass which is whitish in color, pultaceous in consistency of a variable size ranging from a size of a walnut to even measuring over $5 \mathrm{~cm}$ in diameter. Microscopically the lesion is made up of three components, i.e. the cystic content, the matrix and the perimatrix. ${ }^{3}$ Earache, fever, rigors, vomiting vertigo headache and facial paralysis all suggests an impending complication of cholesteatoma. Prior to the advent of the antibiotic era and modern otologic surgery, complications of cholesteatoma were common and usually serious when intracranial tissue planes were involved. Cholesteatoma in children is believed to be more aggressive disease with greater incidence of complications. Cholesteatoma causes complications by bone erosion. However, in the presence of an upper respiratory infection or when water enters the ear, the process of desquamation of keratin is accelerated and secondary infection supervenes. Such a secondary acute infection can cause rapid development of complications. Signs and symptoms are dependent on the location and extent of disease. Cholesteatoma may remain clinically silent for a significant period of time until the 
disease has become quite extensive. Hearing loss and otorrhea are common manifestations, but other more serious intratemporal and intracranial complications may arise. ${ }^{4}$ Surgical therapy is the mainstay of management. The primary surgical objective is eradication of all diseased tissue with a dry safe ear. Maintenance or restoration of hearing is a secondary goal. Management of cholesteatoma requires prolonged, diligent postoperative follow up due to the significant rate of recidivistic disease. This discussion will involve pathogenesis and management of cholesteatoma. Some underlying concepts regarding establishment of the pathologic process will be mentioned, as well as anatomic considerations pertinent to effective management of the condition. A great deal of controversy remains as to the most effective management of cholesteatoma. The various surgical techniques employed will be outlined, followed by treatment results which have been obtained with different approaches to cholesteatoma removal.

Aim \& objective: To study the surgical management of cholesteatoma patients at a tertiary health care centre

\section{MATERIAL \& METHODS}

Present study was an observational study carried out at ENT Department of GOVERNMENT MEDICAL COLLEGE, AURANGABAD. Study population was Patients coming to ENT outpatient department of GOVERNMENT MEDICAL COLLEGE, AURANGABAD with complaints of Ear discharge, Earache and Hearing loss.

Inclusion criteria:

1. Patients with Ear with discharge which may be blood stained, foul smelling (pungent / fishy odor).

2. Patients with attic and posterosuperior quadrant pathology.

3. Patients with evident intracranial complications. 4. Patients with Congenital cholesteatoma with intact tympanic membrane.

Exclusion criteria:

1. Patients with central perforation

2. Patients with Safe dry ear.

3. Patients not willing to participate

A valid written consent was taken from the patients after explaining study to them. Data was collected with pre tested questionnaire. Data included demographic data like age, sex. Clinical history was noted. Present complaints, risk factors and investigations were noted. These cases of cholesteatoma were taken for clinical evaluation, investigations and surgical treatment. After discharge patients advised to come for regular follow up. Complications of surgery noted. Data was entered in excel sheet and analysed with SPSS 20.

\section{RESULTS}

In our study, Adults were most commonly affected (80\%) as compared to children (0-15 yrs) (20\%). Ages were dispersed over a wide range of age groups with a mean age of 24 years. The median age was 22 years (range, 5 years to 55 years.) There was a slight male preponderance (54\%) (Male vs. Female was $54 \%$ vs. $46 \%$ ). Our study revealed otorrhea as the most common presentation (98\%) followed by hearing loss (72\%) post auricular abscesses and fistulae were seen frequently (16\%) Facial palsy was seen in 4\% of pre operative patients. Otorrhea was foul smelling in $96 \%$ of cases and $4 \%$ were non foul smelling in our study. (table 1) Sclerotic mastoid was most commonly seen (82\%) finding followed by diplopic (10\%). Pneumatic mastoid was found in $8 \%$ cases. Our study showed that the majority of the cases $(68 \%)$ belonged to the poor class, $22 \%$ belonged to middle class and $10 \%$ cases belonged to rich class. In our study tympanic membrane pathology was observed. Our study revealed posterosuperior retraction (56\%) to be the most common type in our cholesteatoma series followed by attic retraction (40\%). Postero superior perforation was observed in $2 \%$ and attic perforation was seen in $2 \%$ cases. Our study revealed conductive hearing loss as the most common $31 / 38(82 \%)$ type followed by mixed type $5 / 38$ (13\%). Sensorineural deafness was observed in $2 / 38$ cases. Our study revealed ossicular erosion to be present in $90 \%$ of patients with the erosion of long process of incus being the most common type (44\%) followed by the arch of stapes erosion (20\%). (table 2) Our study showed that $60 \%$ of the patients underwent canal wall down and other (atticotomy) procedures whereas in $40 \%$ of cases the canal wall up procedure was undertaken. Our study revealed that in $80 \%$ of the patients some form of middle ear reconstruction was done whereas in $20 \%$ of patients no reconstruction was undertaken. $25 \%$ of the patients who had undergone radical mastoidectomy had a middle ear reconstruction done as compared to $67 \%$ of modified radical mastoidectomies. (table 3 ) In our follow up of 6 months, the recurrence rate in children was found to be higher (20\%) than in adults (5\%). (fig 1) In our 6 months follow up, we found a slight higher recurrence rate $(10 \%)$ in intact canal wall technique as compared to canal wall down techniques (7\%). (fig 2) 
Table 1: Distribution of patients according to different modes of presentation

\begin{tabular}{ccc}
\hline Symptom & Total No. of cases & Percentage (\%) \\
\hline Otorhhea & 49 & 98 \\
Hearing loss & 36 & 72 \\
Postaural abscess or fistula & 8 & 16 \\
Aural bleeding or aural polyp & 5 & 10 \\
Earache & 8 & 16 \\
Facial palsy & 2 & 4 \\
Vertigo or tinnitus & 2 & 4 \\
\hline
\end{tabular}

Table 2: Distribution of cases according to Per-operative status of ear ossicles

\begin{tabular}{ccc}
\hline $\begin{array}{c}\text { Erosion status of } \\
\text { Ossicles }\end{array}$ & No. of Patients & Percentage (\%) \\
\hline Long process of incus & 22 & 44 \\
Arch of stapes & 10 & 20 \\
Entire malleus & 2 & 4 \\
Head of malleus & 6 & 12 \\
Entire incus & 4 & 8 \\
Handle of malleus & 1 & 2 \\
Not involved & 5 & 10 \\
\hline Total & 50 & 100 \\
\hline
\end{tabular}

Table 3: Type of middle ear reconstructions undertaken for the various surgeries

\begin{tabular}{|c|c|c|c|}
\hline Type of Surgery & $\begin{array}{c}\text { Type of } \\
\text { reconstruction }\end{array}$ & $\begin{array}{c}\text { Total No. of } \\
\text { cases }\end{array}$ & $\%$ \\
\hline \multirow{3}{*}{$\begin{array}{l}\text { Radical Mastoidectomy } \\
\text { (4) }\end{array}$} & Type III & 1 & 2 \\
\hline & tympanoplasty & & \\
\hline & Not done & 3 & 6 \\
\hline \multirow{4}{*}{$\begin{array}{c}\text { Arch of stapes } \\
\text { Modified radical } \\
\text { mastoidectomy (21) }\end{array}$} & 10 & & 20 \\
\hline & Incus reposition & 10 & 20 \\
\hline & Type I or III tympanoplasty & 4 & 8 \\
\hline & Not done & 7 & 14 \\
\hline $\begin{array}{l}\text { Combined approach } \\
\text { tympanoplasty }(20)\end{array}$ & $\begin{array}{l}\text { Combined approach } \\
\text { tympanoplasty } \\
\text { (Type I or II) }\end{array}$ & 20 & 40 \\
\hline Atticotomy(5) & Type I Tympanoplasty & 5 & 10 \\
\hline
\end{tabular}

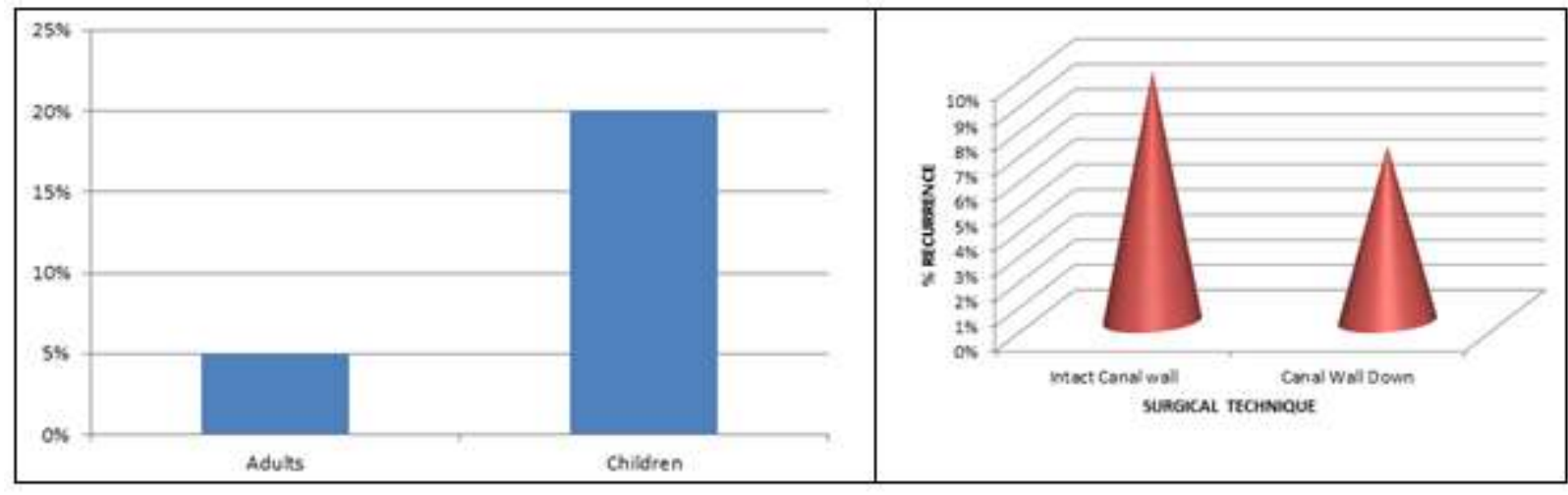

Figure 1

Figure 2

Figure 1: Recurrence rate in patients after reconstructive surgery

Figure 2: Recurrence rate in patients after reconstructive surgery according to type of surgery 


\section{DISCUSSION}

Our study regarding the distribution of cholesteatoma in different age groups revealed that adults were more commonly affected (80\%) as compared to children $(20 \%)$. There was a slight male preponderance (54\%). In a similar study in Papua New Guinea patients Garap JP and Dubey SP (2001) ${ }^{5}$ found that adults were more commonly affected, and there was a male preponderance. The median age was 24 years (in our study $=22$ years) Our study regarding the distribution of cholesteatoma in various socio-economic groups revealed that the majority of our cases were poor. (68\%) The study by Garap JP and Dubey $\mathrm{SP}^{5}$ in Papua New Guinean patients, too revealed that the majority of them were poor. In a study in Greenlanders, Homoe P $(2001){ }^{6}$ found that children had an increased risk of chronic otitis media when living in very crowded households. This may be one the reasons why most of our patients are poor who have presented to us with cholesteatoma. Our study regarding the different modes of presentation of cholesteatoma revealed otorrhea as the most common presentation (98\%) followed by hearing loss (72\%), Postauricular abscesses and fistulae were seen frequently $(16 \%)$. Facial palsy was seen in $4 \%$ of preoperative patients. In a similar study to identify the common presentation(s) Garap JP and Dubey SP ${ }^{5}$ found otorrhea to be the most common presentation in all age groups. In another study of clinical features by Sheahan P. et $\mathrm{al}^{7}$ in Ireland revealed hearing loss (78\%) to be the most common presenting symptom followed by otorrhea (60\%). A great deal of debate exists as to the most appropriate surgical technique for the management of cholesteatoma. Much of the controversy surrounds the use of intact canal wall versus canal wall down mastoidectomy. Many prominent otologic surgeons have considerable differences of opinion in this matter, and there are strong proponents of both approaches. Treatment results are variable in terms of eradication of disease and hearing, and there has been no consensus as to a universally effective treatment strategy. In our study of 50 cases, $60 \%$ underwent canal wall down and $40 \%$ canal wall up procedures. We adopted an individualized approach based on the extent of disease in our study. Dodson et al ${ }^{8}$ study revealed recidivistic disease in $41 \%$ of the patients having intact canal wall mastoidectomy compared with $12 \%$ recidivism in those having a canal wall down procedure with comparable hearing results for the two procedures. The authors feel that with a planned second-stage procedure, in an ear with no mastoid cavity to maintain and good hearing, the canal wall up method is the preferable method to attempt initial eradication unless this method is precluded for other reasons. Hirsch et a ${ }^{9}$ favour the canal wall down approach for removal of cholesteatoma in children due to a lower rate of recidivistic disease and a need for fewer revisions.
Proponents of canal wall down surgery are Chang $\mathrm{CC}$ and Chen MK ${ }^{10}$ who found a low recurrence rate $(3.8 \%)$ and high dry ear rate with this approach. Mills and Padgham ${ }^{11}$ also reported a low residual disease $(6 \%)$ and a high dry ear rate $(70 \%)$ with this approach in childhood cholesteatoma. On the other hand, Ueda $\mathrm{H}$ et al, ${ }^{12}$ proponents of canal wall up surgery, propose to use canal wall up mastoidectomy when possible for paediatric cholesteatoma inspite of the high recurrence rate associated with it (53\% in the early period as compared to $14 \%$ for canal wall down procedures) in view of other postoperative complications, such as erosion of the mastoid cavity, otorrhea and perforation of the eardrum which occurred more frequently in the canal wall down group in their series. Finally the conclusion of Sade $\mathrm{J}^{13}$ needs to be reemphasized who conducted a follow up of 368 cases, operated on according to 6 different surgical modalities. He concluded that there is no single surgical treatment of choice for aural cholesteatoma. The extent of cholesteatoma, the amount of pre-operative destruction, and the size of the mastoid pneumatization should guide the surgeon in choosing the type of operation for a particular ear, which may range from a simple extraction of the cholesteatoma (delivery) all the way to a radical mastoidectomy. In our study, the recurrence rate (on 6 months follow up) in children was found to be much higher $(20 \%)$ than in adults $(5 \%)$. This is comparable with the results obtained in Smyth's ${ }^{14}$ combined canal wall up series where the recurrence rate in children was $24 \%$ compared with $6 \%$ in adults. The eustachian tube anatomy and resulting poor function in children predispose to recurrence of retraction pockets, as well as to otitis media and infection of the cholesteatoma. The aggressive nature of cholesteatoma in children was reinforced by Rosenfeld et al (1992) ${ }^{15}$ who recommended a diligent long term follow up including the necessity of a second look procedure in those children demonstrating ossicular erosion. Our study also revealed a slight higher rate of recurrence in canal wall up procedures (10\%) as compared to canal wall down procedures (7\%). Austin's ${ }^{16}$ study (1989) of 215 patients had revealed a recidivism rate of $4 \%$ for canal wall down and 39\% for canal wall up procedures. The higher rate in Austin's study as compared to our study may be due to the fact that the follow up period in Austin's study was 17 years whereas in our study it was only 6 months. As the follow-up period increases the recurrent rates will also tend to increase.

\section{CONCLUSION}

There is no single surgical treatment of choice for aural cholesteatoma. The extent of the cholesteatoma, the amount of preoperative destruction, and the size of the mastoid pneumatization should guide the surgeon in 
choosing the type of operation for a particular ear,which may range from a simple extraction of cholesteatoma (delivery) all the way to a radical mastoidectomy.

\section{REFERENCES}

1. Youngs R. Chronic Suppurative Otitis Media Cholesteatoma. Chapter 28, Harold Ludman, Tony Wright, Diseases of the ear, Sixth Edition, Arnold, 1998.

2. Abramson $\mathrm{M}$ et al Cholesteatoma pathogenesis : evidence for the migration theory. In : McCabe B, Sade $\mathrm{J}$, Abramson $\mathrm{M}$ eds. Cholesteatoma. First Internationa Conference. Aesculapius : Birmingham, 1977 : 17686.

3. Ferlito A. A review of the definition, terminology, and pathology of aural cholesteatoma. J Laryngol Otol 1993; 107: p. 483-488.

4. Paparella, Shumrick Gluckman, Meyerhoff. Otolaryngology, otology and neurootology, Vol II, 3rd edition. Philadelphia: W.B. Saunders Compan; 1991, Pg.1362-1385.

5. Garap JP, Dubey SP, Canal Wall down mastoidectomy experience in 81 cases. Otology Neurotology . $2001 \mathrm{Jul}$ : 22(4) : 451-456.

6. Homoe P. Otitis media in Greenland, studies on historical, epidemiological, microbiological and immunological aspects. International Journal of Circumpolar health , 2001:60 Supplement 2:1-54.

7. Sheahan P, Donnelly M, Kane R., Clinical features of newly presenting cases of chronic otitis media. Journal of Laryngology and Otology. 2001 Dec : 115 (12) : 962-966.
8. Dodson EE et al, Intact canal wall mastoidectomy with tympanoplasty for cholesteatoma in children. Laryngoscope $1998 ; 108$ : 977-983.

9. Hirsch BE, Kamerer DB, Doshi $S$ : Single stage management of cholesteatoma. Otolaryngology Head and Neck Surgery, $106: 351-354,1992$.

10. Chang CC, Chen MK. Canal Wall down tympanoplasty with mastoidectomy for advanced cholesteatoma. Journal of Otolaryngology 2000.Oct : 29(5) : 270-3.

11. Mills RP. Management of chronic suppurative otitis media, Chapter 10, Scott Brown's Otolaryngology, Volume 3, Otology,6th Edition, Butterworth, Heinemann Ltd., 1997, pp 3/10/7.

12. Ueda H, Nakashima T, Nakata S. Surgical Strategy for cholesteatoma in children. Auris Nasus Larynx 2001 Apr : 28(2) : 125-129.

13. Sade J. Surgical Planning of the treatment of cholesteatoma and postoperative follow up. Annals of Otology, Rhinology and Laryngology. 2000 Apr : 109(4) : 372-376.

14. Smyth GDL. Postoperative cholesteatoma in combined approach tympanoplasty : Fifteen year report on tympanoplasty, Part I, Journal of Laryngology and Otology 90:597-621, 1976.

15. Rosenfeld RM, Moura RL, Bluestone CD. Predictors of residual recurrent cholesteatoma in children. Archives of Otolaryngology and Head and Neck Surgery. 118:384391, 1992.

16. Austin DF: Single- stage surgery for cholesteatoma : An actuarial analysis. American Journal of Otology $10: 419$ 425, 1989.

\section{Source of Support: None Declared Conflict of Interest: None Declared}

\section{Policy for Articles with Open Access:}

Authors who publish with MedPulse International Journal of ENT (Print ISSN: 2579-0854) (Online ISSN: 2636-4727) agree to the following terms: Authors retain copyright and grant the journal right of first publication with the work simultaneously licensed under a Creative Commons Attribution License that allows others to share the work with an acknowledgement of the work's authorship and initial publication in this journal.

Authors are permitted and encouraged to post links to their work online (e.g., in institutional repositories or on their website) prior to and during the submission process, as it can lead to productive exchanges, as well as earlier and greater citation of published work. 